\title{
High Added-Value Co-Product: the Porcine Cruor is an Attractive Source of Active Peptides
}

\author{
Oumaima Zouari ${ }^{1}$, Rémi Przybylski ${ }^{1}$, Mounir Hannioui ${ }^{1}$, Ludivine Sion ${ }^{1}$, Pascal Dhulster ${ }^{1}$, Naïma Nedjar-Arroume ${ }^{1}$ \\ ${ }^{1}$ D1Univ Lille, INRA, ISA, Univ Artois, Univ Littoral Côte d'Opale, EA 7394 - ICV - Institut Charles Viollette, F-59000 Lille, France
}

Received: 02 December, 2019; Accepted: 27 December, 2019; Published: 10 January, 2020

*Corresponding author: Institut Charles Viollette, ProBioGEM, PolytechLille, Université Lille, Avenue Paul Langevin, F-59655 Villeneuve d'Ascq Cedex, France, Tel: + 333287673 90; Fax : + 33328767356 E-mail: naima.nedjar@univ-lille.fr

\begin{abstract}
The porcine cruor represents a co-product from slaughterhouses. It mainly contains hemoglobin which is rich in bioactive peptides obtained by hydrolysis by porcine pepsin. The aim of this study is to valorize this new source rich of bioactive peptides to be used as feed additives. An in silico study on the potential of porcine cruor to contain bioactive peptides was studied by comparing it with peptides derived from bovine hemoglobin. The blast results showed a high similarity between porcine cruor hydrolysate peptides and bovine hemoglobin hydrolysates for both $\alpha$ and $\beta$ chains with identities of $87 \%$ and $83 \%$ respectively. Cleavage sites of porcine cruor were also predicted using Peptide Cutter software and compared with bovine hemoglobin. Results reveal the preservation of most of peptides of porcine cruor hydrolysates comparing to bovine hemoglobin hydrolysates. The presence of bioactive peptides was then determined by mass spectrometry analysis. Results showed the presence of 37 bioactive peptides defined by their sequences found in previous study with mainly antibacterial and opioid peptides. The antibacterial activity was then verified by in vitro analysis against 4 bacterial strains. Results showed interesting MIC values comparing with tested synthetic peptides ( $4.53 \mu \mathrm{M}$ for M.luteus and L.innocua, $35.94 \mu \mathrm{M}$ for E.coli and $312 \mu \mathrm{M}$ for S.newport). The antioxidant activity was also verified by studying DPPH $\bullet+$ trapping and results showed an antiradical activity for porcine cruor hydrolysate greater than neokyotorphin which was previously validated as a natural preservative to substitute synthetic additives against food alteration ( $14 \%$ and $10 \%$ respectively). These similarities of porcine cruor hydrolysate in peptic profiles as well as biological activities make it a new interesting source of bioactive peptides.
\end{abstract}

Key Words: Hemoglobin; hydrolyzate; porcin; bovin; cruor; antibacterial; antioxidant

\section{Introduction}

Blood is a co-product of slaughterhouses that is very rich in protein. It contains about $17.8 \%$ in cattle and $18.5 \%$ in pigs [1]. The potential of these numerous co-products remains underestimated and under-exploited. To move towards a sustainable economy, the valuation of these co-products becomes a capital issue. These non-valued raw materials currently constitute new resources with high recovery potential. The role of these dietary proteins as a source of biologically active peptides is widely described in recent studies. Numerous databases on active peptides are developing for referencing these activities [2]. Hemoglobin accounts for more than half of these proteins [3]. Bovine hemoglobin is known to be a source of peptides presenting biological activities [4]. This protein is the source of many peptides whose antimicrobial, antioxidant, antihypertensive, opioid bacterial growth stimulant, hematopoietic activities have been described in the literature [5-16].

Blood from slaughterhouses is divided into two parts, plasma and cruor. The colorless fraction corresponds to the plasma and is generally separated by centrifugation. It represents approximately $60 \%$ of the blood volume. The cruor, a co-product of slaughterhouses, accounts for $40 \%$ of blood volume, including 70 to $75 \%$ of total blood protein, but it is currently poorly valued. This fraction is responsible for the unstable red color of the blood and contains more than 90\% hemoglobin [17]. Recently, a study conducted on bovine cruor showed the presence of an antimicrobial peptide, $\alpha 137-141$. The application of this peptide as a preservative on meat has shown a $60 \%$ reduction in rancidity delay [9].

The present study consists in the description of the valued raw material: the cruor as well as its composition. Then, the different bioactive peptides obtained by enzymatic hydrolysis of hemoglobin identified in the literature are listed according to their activity described. The prediction of these bioactive peptides by the pepsin hydrolysis of porcine cruor was performed by bioinformatics approach. Thus, a comparative study of porcine cruor hydrolysate with respect to bovine cruor hydrolysate was conducted to define the similarities in peptides generated and the presence of bioactive peptides.

\section{Materials and Methods}

Production of Porcine Peptides

A stock solution of porcine purified hemoglobin or cruor was prepared by adding $15 \mathrm{~g}$ of each product in $100 \mathrm{~mL}$ of water. The hemoglobin concentration was given by the Drabkin test [18]. Thus the stock solution is diluted to obtain a final solution at $1 \%$ or $8 \%(\mathrm{w} / \mathrm{v})$ in hemoglobin. The volume of stock solution is adjusted to $150 \mathrm{~mL}$, to which $25 \mathrm{~mL}$ of sodium acetate-acetic acid buffer (0.5 M, pH 3.5) are added [19]. The pH of the reactor is adjusted to 3 with hydrochloric acid (2M). The protein digestion was carried out using porcine pepsin (EC 3.4.23.1, 3200 - 4000 units mg-1 protein) which were prepared in $25 \mathrm{~mL}$ of sodium 
acetate-acetic acid buffer $(0.1 \mathrm{M}, \mathrm{pH} 3.5)$. The hydrolysis was followed for times ranging from 0 - 24 hours. After these reactions were stopped by addition of sodium hydroxide (1 M) up to $\mathrm{pH}$ 9 for enzyme denaturation. Experiences have been carried out in triplicate and samples were preserved at $-20^{\circ} \mathrm{C}$ for further analysis.

\section{Determination of the Degree of Hydrolysis}

To measure the degree of hydrolysis OPA (orthophthaldialdehyde) was used as a reagent. For this $100 \mathrm{mg}$ of sodium dodecyl sulfate (SDS) and $4.14 \mathrm{~g}$ of di-Sodium tetraborate are solubilized in $70 \mathrm{~mL}$ of ultrapure water. $80 \mathrm{mg}$ of OPA are dissolved in $2 \mathrm{~mL}$ of ethanol to which $88 \mathrm{mg}$ of Dithiothreitol (DTT) are added. The two previous solutions are mixed and adjusted to $100 \mathrm{~mL}$ with ultrapure water. The prepared reagent is filtered with a $0.2 \mu \mathrm{m}$ cellulose acetate filter and stored in obscurity. The assay of the hydrolysates is then carried out on $100 \mu \mathrm{L}$ of sample, previously diluted to 10th, and brought into contact with $3 \mathrm{~mL}$ of reagent with OPA. The absorbance at $340 \mathrm{~nm}$ is read after 3 minutes. The degree of hydrolysis is determined by the formula:

$$
D H=\frac{\mathrm{h}}{\mathrm{h} \text { total }}
$$

With: h: number of hydrolyzed peptide bonds

h total: number of total peptide bonds: 568 for hemoglobi

\section{Identification of peptides by LC MS / MS}

Charts LC MS/MS were performed on a UFLC-XR (Shimadzu) coupled to a QTRAP(R) $5500 \mathrm{MS} / \mathrm{MS}$ triple quadrupole associated with a linear spectrometer ion trap mass (AB Sciex, Foster City, CA, USA) equipped with a Turbo VTM ion source. The analyzes were carried out in positive ionization mode using a $5500 \mathrm{~V}$ Ion Spray. The nebulizer gas is air and nitrogen curtain gas at a flow rate of $30 \mathrm{psi}$. The Turbo VTM source was used at $550^{\circ} \mathrm{C}$ with air as an auxiliary gas at 50 psi. Analyst 1.5 .2 software was used for device control and data acquisition. All analyzes were carried out through a C18 column. The mobile phase is composed of ultrapure water / formic acid (1000:1, V/V) for eluent A and acetonitrile / ultrapure water / formic acid (600: 400: 1; V/V/V) for eluent B. The samples were filtered through PVDF filters $(0.20 \mu \mathrm{m})$ before being analyzed and then $5 \mu \mathrm{L}$ of each sample were injected. The elution program is $100 \%(\mathrm{~V} / \mathrm{V}$ ) of the eluent $\mathrm{A}$ for 5 minutes to remove the inorganic salts, then it goes from $0 \%$ to $67 \%(\mathrm{~V} / \mathrm{V})$ of the eluent B during 25 minutes with a flow rate of $0.6 \mathrm{~mL} /$ min. Results were analyzed using BioAnalystTM 1.5.1 (ABSciex, Darmstald, Germany) and Peaks(R) 7 (Waterloo, Canada).

\section{Comparison of Peptide Sequences by Bioinformatics Approach}

The software used for this study is BLAST® ((Basic local Alignment Search Tool), available online at https://blast.ncbi. nlm.nih.gov/Blast.cgi . The algorithm used by blast is the SmithWaterman algorithm, which allows for quick alignment while maintaining good sensitivity.

\section{Prediction of Clipping Sites by Bioinformatics Approach}

Peptide Cutter software from ExPASy was used for the prediction of the peptide population resulting from the pepsin hydrolysis of bovine or porcine hemoglobin. It is accessible free of charge by following the link: https://web.expasy.org/peptide_ cutter/. The Peptide Cutter tool allows the prediction of potential cleavage sites in a protein sequence given by proteases. This software returns the query sequence with the possible cleavage sites mapped to it and a table of cleavage site positions.

\section{Determination of Antibacterial Activity and Minimal Inhibitory Concentration (MIC)}

Detection of the antimicrobial activity of porcine cruor hydrolysates or synthetic peptides was performed in our laboratory according to the method of Adje et al. [8]. Pre-culture of the strains is carried out by inoculation: $50 \mu \mathrm{L}$ of bacteria are introduced into $5 \mathrm{~mL}$ of Müller-Hinton medium (MH), the whole is incubated for $18-24 \mathrm{~h}$ at $37^{\circ} \mathrm{C}$. After homogenization, the absorbance of the cultures is determined spectrophotometrically at $600 \mathrm{~nm}$ against the medium $\mathrm{MH}$ alone. In order to obtain an absorbance of 0.25 to $600 \mathrm{~nm}$, serial dilutions are carried out in Tryptone Sel (TS), phosphate buffer, depending on the type of bacteria, to obtain a final Colony Forming Unit of 106 CFU/ $\mathrm{mL}$. Seeding of the strains onto the agar plates was done by the flooding method. Then $5 \mu \mathrm{L}$ of the samples to be tested were deposited on the agar by spotting. The results are read after incubation of the agar plates at $37^{\circ} \mathrm{C}$ for 24 hours.

The minimal inhibitory concentration was determined by bacterial growth inhibition in 96-well microplate [6]. $50 \mu \mathrm{L}$ of cell suspension adjusted at $106 \mathrm{UFC} / \mathrm{mL}$ were disturbed in the microplate's wells containing $50 \mu \mathrm{L}$ of hydrolysates and $50 \mu \mathrm{L}$ of Muller-Hinton broth. MIC corresponds to lower concentration of hydrolysate that inhibit completely the strain growth after $24 \mathrm{~h}$ of incubation at $37^{\circ} \mathrm{C}$.

\section{Trapping of DPPH• Radicals}

The ability of hydrolysates to capture the DPPH $\bullet+$ (2,2-diphenyl-1-picrylhydrazyl) radical is determined by a spectro photometric method recently described by Molyneux [20]. An ethanoic stock solution of DPPH $\bullet+(0.02 \%$ by weight $)$ is prepared 12 to 16 hours before use. The hydrolysates tested are dissolved beforehand at $40 \mathrm{mg} / \mathrm{mL}-1$ and then a volume of $200 \mu \mathrm{L}$ is diluted in $5 \mathrm{~mL}$ of water. Then, a volume of $500 \mu \mathrm{L}$ of sample is mixed with $250 \mu \mathrm{L}$ of ethanol ( $99.5 \%$ by mass) to which $375 \mu \mathrm{L}$ of the DPPH solution are added. The whole is mixed by vortex. The absorbance of the mixture is measured after 1 hour of incubation at $30^{\circ} \mathrm{C}$ in obscurity against pure ethanol at $517 \mathrm{~nm}$ which is used as blank. The purified neokyotorphin was used as a reference of an antioxidant peptide at $2.5 \mathrm{mg} . \mathrm{ml}-1$. The Radical Scavenging Activity (RSA) is expressed as a percentage and is given by the following formula:

$$
\operatorname{RSA}(\%)=\frac{(\text { absorbance controle }+(\text { Absorbance blank }- \text { Absorbance sample }))}{\text { Absorbance control }}
$$


With Absorbance control is the absorbance of pure ethanol and Absorbance blank is the absorbance without DPPH.

\section{Results and Discussion}

\section{A kinetic study of porcine hemoglobin by pepsin}

The kinetics of hydrolysis of cruor by pepsin was studied for several hydrolysis times from 0 min to $24 \mathrm{~h}$ in order to have different degrees of hydrolysis and thus to be able to observe different peptide populations. Each sample was analyzed by reverse phase HPLC to study the peptide population. The chromatographic profiles of the hydrolysates of porcine cruor show a resemblance with the peptide hydrolysates derived from bovine cruor. For the chromatograms representing 1\% native hemoglobin, the unhydrolyzed sample at $215 \mathrm{~nm}$ shows that the hem has the shortest retention time, so it leaves first. It is followed by the $\alpha$ chain and $\beta$ chain of hemoglobin. Over time, a change in the peptide population of hydrolysates is observed.
After 2.5 minutes of hydrolysis, the $\alpha$ and $\beta$ chains of hemoglobin disappeared in favor of a large mass of peptides eluted before them. It can be seen that as the degree of hydrolysis increases, the retention time of this peak mass decreases, which means that the hydrophobic peptides are initially cleaved into smaller peptides then becoming more and more hydrophilic. From this observation the mechanism involved here is of the "zipper" type, which means that swine hemoglobin is rapidly converted into intermediate peptides, which will also be hydrolyzed into smaller peptides. However, as the Linderston-Lang theory demonstrates the mechanism should be the "one by one" type, this difference being explained by the fact that the hemoglobin is denatured at $\mathrm{pH} 3.5$ even in the absence urea [22]. So we have 2.5 and 30 minutes of hydrolysis of large peptides at longer retention times, then the appearance of peptides of intermediate size for hydrolysis of 10 hours and finally at 24 hours, we have peptides of small size coming out faster Figure 1.

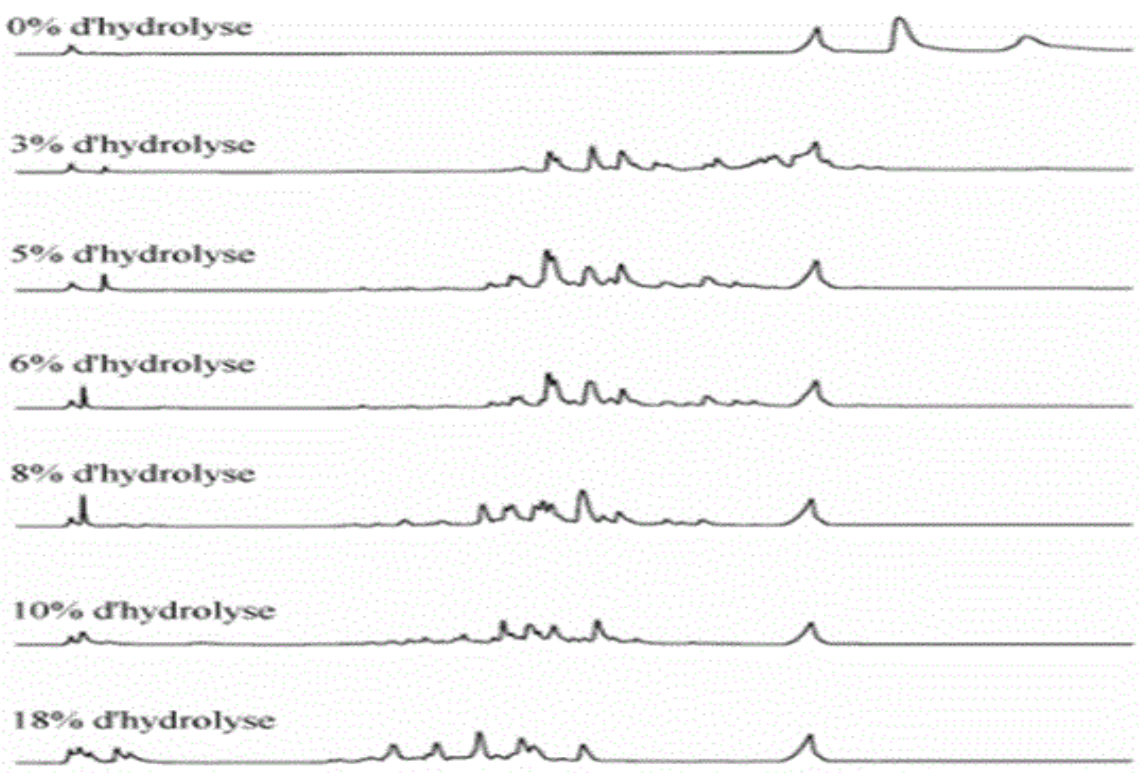

Figure 1: Chromatogram showing the kinetics of hydrolysis of the porcine cruor during $24 \mathrm{~h}$ at $\mathrm{pH} 3$ and $\mathrm{E} / \mathrm{S}=1 / 11$ and at $\mathrm{T}=23{ }^{\circ} \mathrm{C}$

Comparison between Bovine Hemoglobin and Porcine Hemoglobin in Silico

The blast was performed to compare the bovine hemoglobin $\alpha$ (bos Taurus) and of porcine hemoglobin (sus scrofa). The results show that the alpha and beta chains of bovine or porcine hemoglobin are identical in pairs Figure 2a. The $\alpha$ chains of bovine and porcine hemoglobin are both composed of 142 amino acids, so there are no Gaps during sequence alignment. The score obtained is 244 , it corresponds to the statistical measure of the validity of the alignment. The high score indicates that the two compared sequences are similar. The Expect value (e-value) is $9.10-90$, which is so close to zero. We then consider that the pairing is not hazardous. It is observed that the $\alpha$ chains of bos taurus and sus scrofa have many similarities in their amino acid sequences: 123 out of 142 are strictly aligned, the value of the identity obtained is $87 \%$. By coumpting amino acids, this positive value rises to $89 \%$. This alignment of the $\alpha$ chains of hemoglobin makes it possible to observe that the peptides GAEALER (hematopoietic), LANVST (analgesic and potentiator of bradykinin), ANVST (inhibitor of DPP-IV) and TSKYR (opioid) are preserved [16, 23, 24, 25]. In contrast, the VAAA and TKAVEH (DPP-IV inhibitor) and KLLSHSL (antihypertensive) peptides are found only in bos taurus bovine hemoglobin $[12,25]$. The same study was carried out in order to align the amino acid sequences of the $\beta$ chains of hemoglobin bos Taurus and sus scrofa. The $\beta$ chain of bos taurus contains 145 amino acids against 147 for the $\beta$ chain of sus scrofa. After sequence alignment, 144 amino acids were compared. The score obtained (240), the expect value (5.10- 
91) and the value of gaps (0\%). The identity between these two $\beta$ chains is $83 \%$ and rises to $89 \%$ taking into account similar amino acids Figure $2 \mathrm{~b}$. This alignment of hemoglobin $\beta$-chains shows the conservation of VVYP (lipid-lowering), LVVYPWTQRFF (opioid) and VAGVANALAHKYR (coronary-constrictor) peptides [23, 26, 27]. In addition, modification of the STADA peptide (stimulator of bacterial growth) of bos taurus hemoglobin to SNADA peptide in the $\beta$ chain of hemoglobin sus scrofa as well as the modification of KAAVT (inhibitor of DPP-IV) [15, 25].

a)

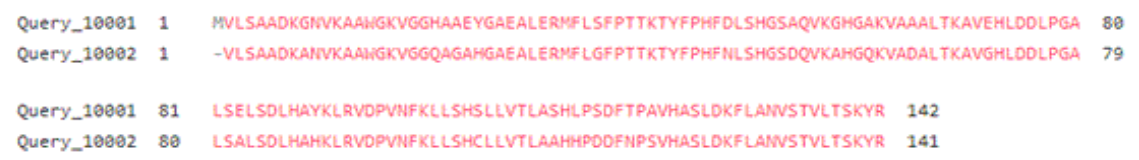

b)

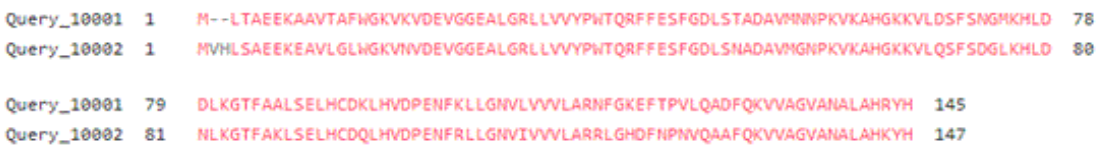

Figure 2: Blast of hemoglobin bos taurus bovine hemoglobin; Query_10001 and sus scrofa; Query_10002 a) alpha chain, b) beta chain

\section{Bioinformatics Approach to Predict Peptides Derived from the Pepsic Hydrolysis of Bovine Hemoglobin and Porcine Hemoglobin}

The sequences of $\alpha$ and $\beta$ chains of bovine hemoglobin (bos Taurus) and hemoglobin porcine (sus scrofa), from NCBI, were submitted to the Peptide Cutter software. The predicted cleavage sites of the alpha chains bovine hemoglobin and porcine hemoglobin by pepsic hydrolysis at $\mathrm{pH}$ higher than 2 are shown in Figure 3a. There are 43 and 40 cleavage sites respectively. Only 3 different cleavage sites were identified by Peptide Cutter, identified by arrows. The peptide profile by pepsic hydrolysis of the alpha chain is therefore similar for bos taurus and sus scrofa. For the alpha chain of porcine hemoglobin, the first two missing cleavages are those for obtaining the GAEALER hematopoietic peptide [16]. By prediction, this peptide will not be found during the hydrolysis of porcine hemoglobin.

For the pepsic hydrolysis of the $\beta$ chain the same study was carried out. The cleavage sites predicted by Peptide Cutter, for the pepsic hydrolysis, of the $\beta$ chains of bovine hemoglobin and porcine hemoglobin at $\mathrm{pH}$ higher than 2, are presented in Figure $3 \mathrm{~b} .42$ potential cleavages have been identified for each of the chains but they are not identical: 10 sites of different cuts were identified by arrows. Taking into account the similar amino acids, the identity between these two chains beta bos taurus and sus scrofa given by Blast rises to $89 \%$ figure 4 . Note that for the beta chain of porcine hemoglobin, the last cleavage results in cleavage of the coronary-constrictor peptide VAGVANALAHKYR [20]. By prediction, this peptide will not be found during the hydrolysis of porcine hemoglobin alone. The peptides VVYP (hypolipidaemic), LVVYPWTQRFF (opioid) and STADA (stimulator of bacterial growth, hemoglobin bos taurus only) are preserved by pepsic hydrolysis at $\mathrm{pH}>2$ according to Peptide Cutter $[26,27]$.

Identification of the Active Peptides in the Porcine Cruor Hydrolysate Compared with those Identified in the Hydrolysate of Bovine Hemoglobin

The LC-MS/MS analyzes were carried out on purified hemoglobin hydrolysate and porcine cruor hydrolysate. The results were acquired using the Mass Lynx software. For each identified peak, the mass of the majority of the peak compound is essentially mentioned. The profile displays the presence of masses $(\mathrm{m} / \mathrm{z})$ between 216.98 Da and 2235.1 Da for cruor hydrolysate. To go further, the mass analysis was coupled to an ESI source (ions electron spray) data to have more voluminous MS/MS analysis data. The data was acquired using the Peaks ${ }^{\circledR}$ software. The sequences of the $\alpha$ and $\beta$ chains of bovine hemoglobin were taken as model proteins for the detection of peptides by Peaks ${ }^{\circledR}$ software. Compared to the identified peptides derived from hemoglobin, 37 active peptides are detected in the porcine cruor hydrolysate Table 1 . Totally, 12 opioid peptides have been detected in porcine cruor hydrolysates. According to the literature, opioid peptides have analgesic properties, and may be potential pharmacological substitutes for pain treatments. Detected TSKY and TSKYR peptides have a role in regulating the $\mathrm{Ca}++/ \mathrm{K}+$ dependent potential in cardiac fibers in the frog [29]. The porcine cruor hydrolysates also contain an interesting number of identified antibacterial peptides compared to those of bovine hemoglobin. The first antimicrobial peptide isolated from the enzymatic hydrolysis of bovine hemoglobin is the $\alpha 1-23$ peptide, active against Micrococcus luteus A270 [6]. Other peptides with antimicrobial activity were then discovered by fractionation of hemoglobin peptomic hydrolysate, some fractions of which have antibacterial activity against four bacteria: Micrococcus luteus, 
(a)
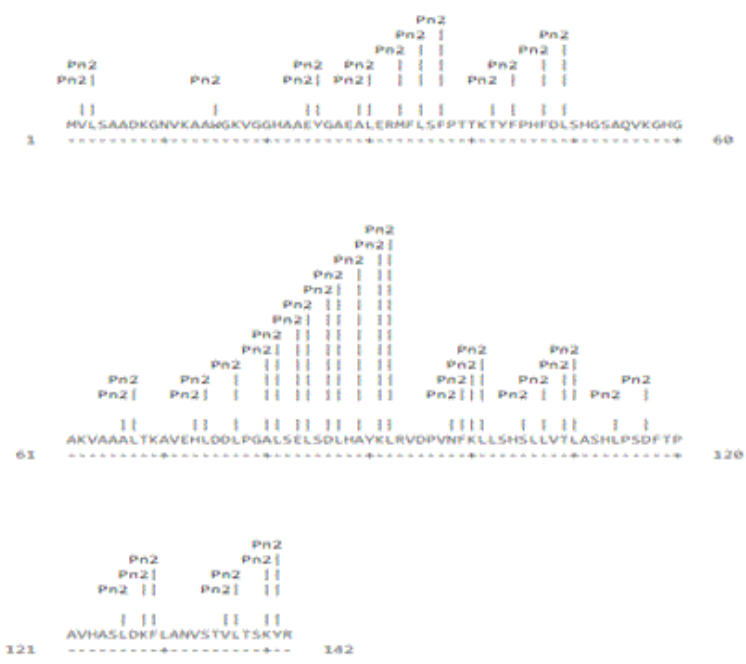

(b)
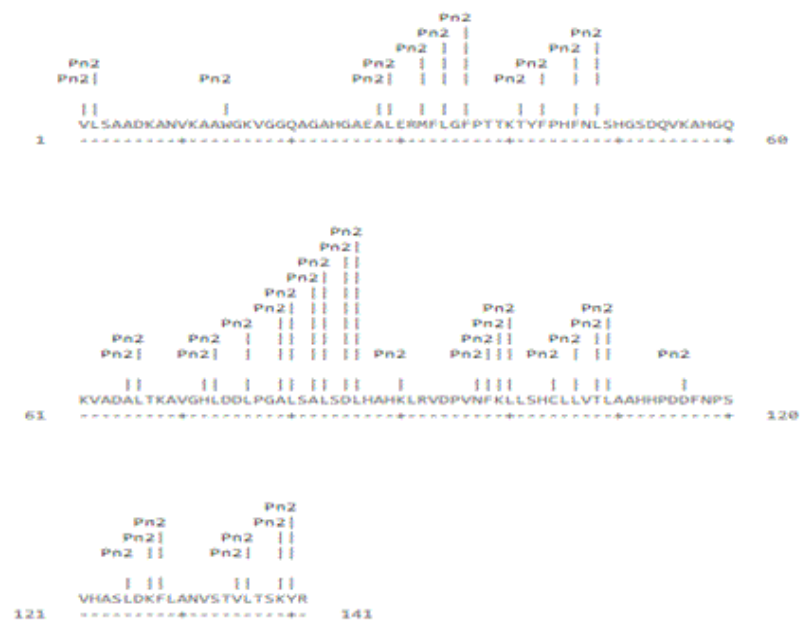

Figure 3: Peptide Cutter: Sites of potential cleavage of the alpha chain of hemoglobin by pepsin at $\mathrm{pH}>2$ : bos taurus (a) sus scrofa (b) The arrows indicate predicted cleavage sites which differ for only one of the 2 alpha chains of hemoglobin

Listeria innocua, Escherichia coli and Salmonella enteritidis. Thirty peptides have been identified after purification: 24 come from the $\alpha$ chain of hemoglobin and 6 are derivatives of the $\beta$ chain of hemoglobin [7]. Other peptides with interesting activities were also detected in porcine cruor hydrolysates such as hematopoietic, which consist of helping to form arm red blood cells in the bone marrow and bone. This activity has been observed in previous studies in peptides derived from chemical hydrolysis [16]. Other activities were also found in porcine cruor generated peptides which are mostly observed in bovine hemoglobin such as, antihypertensive, bradykinin potentiators, coronary-constrictors and DPP-IV inhibitory [12, 23, 25, 26].

\section{The Antibacterial Activities of the Porcine Cruor or Hemoglobin Hydrolysates}

The porcine cruor hydrolysates and peptides identified below as antimicrobial were tested. The results in agar plates showed that all of them were active against the tested strains Table 2. Then the MIC was determined. The MIC is $4.53 \mu \mathrm{M}$ of peptides for 24 hours of hydrolysis for strains Micrococcus luteus ATCC 9341 and Listeria innocua CIP 80.11.T. For Escherichia coli ATCC 25922, the MIC is 35.94 $\mu$ M and 312.5 $\mu$ M for Salmonella Newport ATCC 6962. For the peptides these values were lower for the neokyotorphin TSKYR and generally higher for KLLSHSL and KLLSHSLL. The neokyotorphin is well as an antibacterial peptide with a nonclassical mechanism. It acts by an electrostatic adsorption with the membrane and by insertion of the hydrophobic part in the membrane which provides pore formation. For the valuation of cruor hydrolysates as feed additive, the absence of salmonella must be verified. Staphylococcus aureus is also a main causes of infection, including skin, soft tissues, blood and lungs in humans and animals [30]. Salmonella enterica Newport Serotype, isolated from food and feed, is known to be resistant to at least nine antimicrobials [31]. The addition of hydrolysate to the bactericidal would be a solution to contain the contaminations if necessary. The hydrolysates have an inhibitory effect on the bacterial growth of these strains. The antimicrobial effect of hydrolysate of buttermilk protein gave a MIC of $5 \mathrm{mg} / \mathrm{mL}$ for Escherichia coli versus $2.3 \mathrm{mg} / \mathrm{mL}(35.04 \mu \mathrm{M})$ for the cruor hydrolysate at 24 hours of hydrolysis. In poultry feeding, these results are promising for the development of an alternative or supplement for reducing the use of antibiotics [32].

\section{Trapping of DPPH・ radicals}

All the results obtained by measuring the antiradical activity were determined by the DPPH $\bullet+$ radical inhibition method. For cruor hydrolysate, the antiradical activity was determined for several times of hydrolysis, ranging from 0 to 24 hours. The antiradical activity of neokyotorphin was measured at a concentration of $2.5 \mathrm{mg} / \mathrm{mL}$ and for the cruor hydrolysates it was determined for a concentration of $2.5 \mathrm{mg} / \mathrm{mL}$. The results show that the antiradical activity (RSA) of the $\mathrm{DPPH}^{\circ+}$ test increases with the hydrolysis time up to a certain level and the best activity was observed between $18 \mathrm{~h}$ and $20 \mathrm{~h}$ of hydrolysis Figure 5. At this time, the porcine cruor hydrolysates have an RSA close to $14 \%$. Neokyotorphin, which is an antioxidant peptide, has an RSA of $10 \% \pm 1 \%$ at a concentration of $2.5 \mathrm{mg} / \mathrm{mL}$. In addition, the porcine cruor hydrolysates have an RSA close to $10 \%$. However, the porcine cruor hydrolysate activity is slightly higher than the neokyotorphin activity which was tested for its antioxidant activity in previous studies and showed an interesting activity against meat oxidation [9]. 
Table 1: List of active peptides identified in the porcine cruor hydrolysate, compared with the active peptides of the bovine hemoglobin

\begin{tabular}{|c|c|c|c|}
\hline Activity & Peptide & Chain & Mass $\mathrm{m} / \mathrm{z}$ (da) \\
\hline \multirow{11}{*}{ Antibacterial } & VLSAADKGNVKAAWGKVGGHAAE & $\alpha$ & 2235 \\
\hline & LSFPTTKTYFPHF & $\alpha$ & 1584 \\
\hline & FРТTКТYFРНF & $\alpha$ & 1384 \\
\hline & PTTKTYFPHF & $\alpha$ & 1237 \\
\hline & KLLSHSLL & $\alpha$ & 909 \\
\hline & KLLSHSL & $\alpha$ & 796 \\
\hline & LAHRYH & $\beta$ & 795 \\
\hline & LLSHSL & $\alpha$ & 668 \\
\hline & STVLTSKYR & $\alpha$ & 1054 \\
\hline & FPTTKTYFPH & $\alpha$ & 1210 \\
\hline & TSKYR & $\alpha$ & 635 \\
\hline \multirow{2}{*}{ Dpp-iv inhibitor } & ANVST & $\alpha$ & 490 \\
\hline & KAAVT & $\beta$ & 488 \\
\hline Coronaro-constrictor & VAGVANALAHRYH & $\beta$ & 1377 \\
\hline \multirow{12}{*}{ Opioid } & LVVYPWTQRF & $\beta$ & 1307 \\
\hline & VVYPWTQRF & $\beta$ & 1194 \\
\hline & LVVYPWT & $\beta$ & 876 \\
\hline & VVYPWT & $\beta$ & 763 \\
\hline & TSKY & $\alpha$ & 479 \\
\hline & TSK & $\alpha$ & 316 \\
\hline & YR & $\alpha$ & 319 \\
\hline & LVVYPWTQR & $\beta$ & 1142 \\
\hline & VVYPWTQR & $\beta$ & 1029 \\
\hline & YPWTQR & $\beta$ & 831 \\
\hline & YPWT & $\beta$ & 547 \\
\hline & TSKYR & $\alpha$ & 635 \\
\hline \multirow{8}{*}{ Hematopoietic } & MLTAEEKAAVTA & $\beta$ & 1233 \\
\hline & MLTAEEKAAVT & $\beta$ & 1162 \\
\hline & LTAEEKAAVTA & $\beta$ & 1102 \\
\hline & LTAEEKAAVT & $\beta$ & 1031 \\
\hline & GAEALER & $\alpha$ & 726 \\
\hline & EALE & $\alpha$ & 442 \\
\hline & VGGEALGRLL & $\beta$ & 965 \\
\hline & LPGALSE & $\alpha$ & 685 \\
\hline \multirow{2}{*}{ Anti-hypertensive } & KLLSHSL & $\alpha$ & 796 \\
\hline & LLSHSL & $\alpha$ & 668 \\
\hline Potentiator of bradykinin & LANVST & $\alpha$ & 603 \\
\hline
\end{tabular}


High Added-Value Co-Product: the Porcine Cruor is an Attractive Source of Active Peptides

Table 2: Determination of MIC $(\mu \mathrm{M})$ of porcine cruor hydrolysate at 24 hours of hydrolysis for different strains tested

\begin{tabular}{|c|c|c|c|c|}
\hline & Micrococcus luteus ATCC 934 & $\begin{array}{c}\text { Listeria } \\
\text { Innocua } \\
\text { CIP } 80.11\end{array}$ & Escherichia coli ATCC 25922 & Salmonella Newport ATCC 6962 \\
\hline $\begin{array}{l}\text { Porcine cruor } \\
\text { hydrolysate }\end{array}$ & 4.53 & 4.53 & 35.94 & 312.50 \\
\hline TSKYR & 4.50 & 0.50 & 4.50 & 2.50 \\
\hline KLLSHSL & 19.50 & 19.50 & 39 & 49 \\
\hline KLLSHSLL & 17 & 17 & 34 & 44 \\
\hline
\end{tabular}

(a)
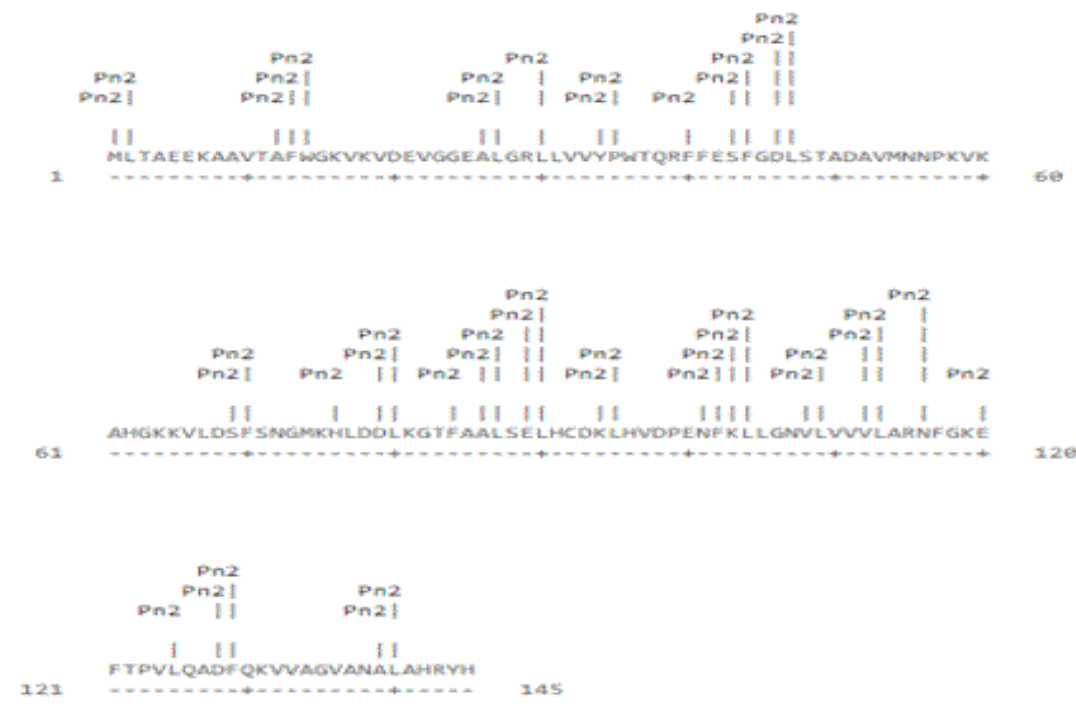

(b)

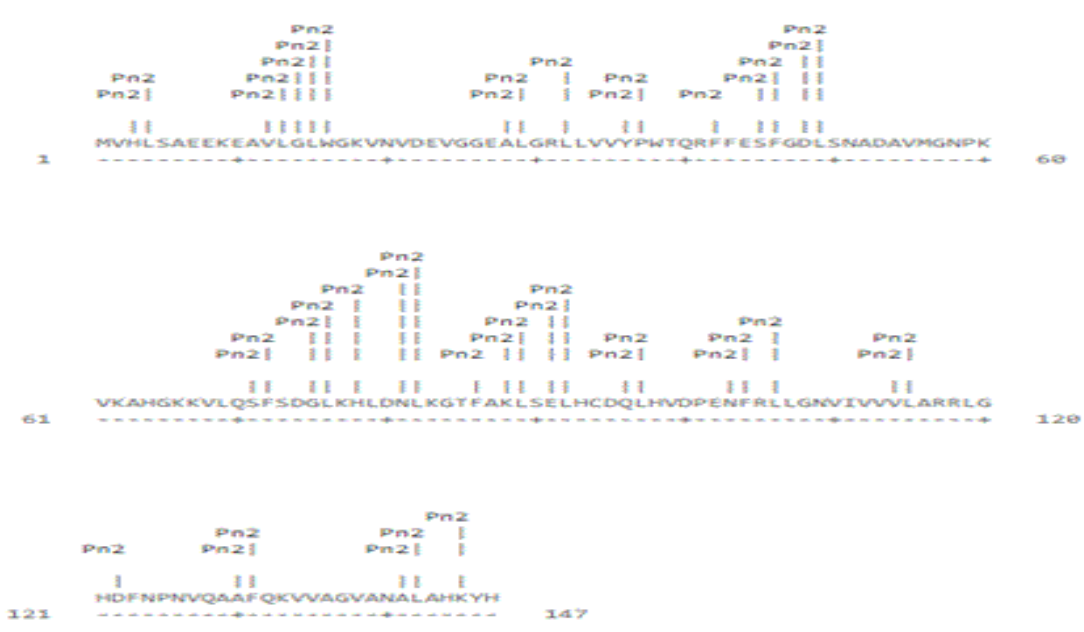

Figure 4: Peptide Cutter: Sites of potential cleavage of the beta chain of hemoglobin by pepsin at $\mathrm{pH}>2$ : bos Taurus (a) sus scrofa (b) The arrows indicate the predicted cleavage sites that differ for only one of the 2 beta chains of hemoglobin 


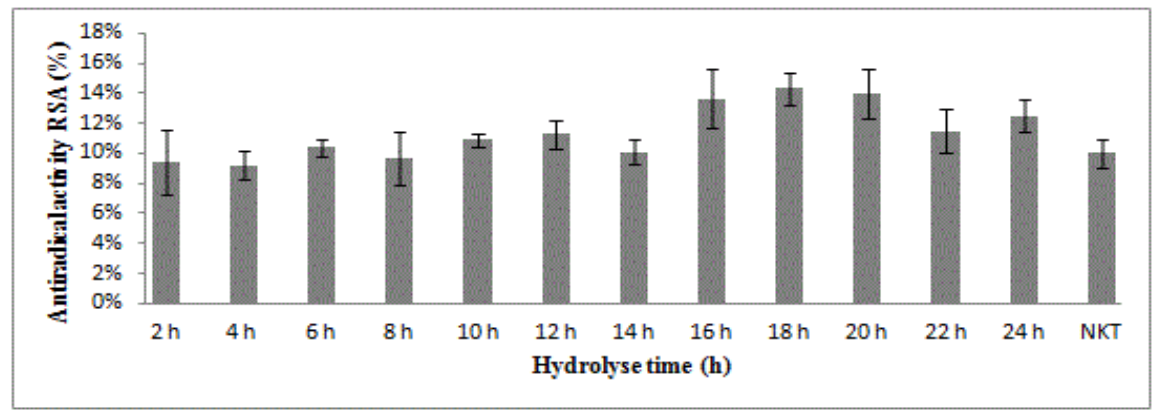

Figure 5: Blast of hemoglobin bos taurus bovine hemoglobin; Query_10001 and sus scrofa; Query_10002 a) alpha chain, b) beta chain

\section{Conclusion}

This study aimed to compare the porcine cruor hydrolysate which is anew potential source of hemoglobin to bovinehemoglobin hydrolysate which is well-known as bioactive peptides source. In silico study was carried out using bioinformatics alignment between the two sequences and showed a high similarity between the derived peptides from the two products with the preservation of the most of identified bioactive peptides. The antibacterial activity was verified for porcine cruor hydrolysates and showed interesting CMI comparing to synthetic antibacterial peptides. The DPPH radical trapping was also studied and results showed an RSA slightly higher than neokyotorphin peptide. To conclude the studied products are very similar in derived peptides structures as well as their activities which make of the porcine cruor a new alternative to be valorize as additives. In the current context of food safety and food protection by means of natural products, such many antibacterial peptides derived from porcine hemoglobin would be interesting as preservatives for storage and distribution of porcine meat based products.

\section{Acknowledgement}

The authors are grateful to the Advanced High Throughput Technologies Platform for Biorefineries Catalysts Design 'REALCAT' for allowing the implementation of MALDI-ToF mass spectrometry analysis.

\section{References}

1. Mora L, Reig M, Toldrá F. Bioactive peptides generated from meat industry by-products. Food Research International. 2014;65(C):344-349.

2. Toldrá F, Reig M, Aristoy C, Mora L. Generation of bioactive peptides during food processing. Food Chemistry. 2018;267:395-404.

3. Ofori JA, Hsieh YHP. Blood-derived products for human consumption. Revelation and Science. 2011;1(1):14-21.

4. Fernandez de Caleya R, Gonzalez-Pascual B, Garcia-Olmedo F, Carbonero P. Susceptibility of Phytopathogenic Bacteria to Wheat Purothionins In Vitro. Appl Microbiol. 1975;23(5):998-1000.

5. Fogaça AC, Da Silva PI, Teresa M, Miranda M, Bianchi AG, Miranda A, et, al. Antimicrobial activity of a bovine hemoglobin fragment in the tick Boophilus microplus. J Biol Chem. 1999;274(36):25330-25334.
6. Froidevaux R, Krier F, Nedjar-Arroume N, Vercaigne-Marko D, Kosciarz $\mathrm{E}$, Ruckebusch C, et al. Antibacterial activity of a pepsin-derived bovine hemoglobin fragment. FEBS Lett . 2001;491(1-2):159-163.

7. Nedjar-Arroume N, Dubois-Delval V, Yaba Adje E, Traisnel J, Krier F, Mary P, et al. Bovine hemoglobin: an attractive source of antibacterial peptides. Peptides. 2008;29(6):969-977. doi: 10.1016/j. peptides.2008.01.011

8. Adje EY, Balti R, kouach M, Dhulster P, Guillochon D, Nedjar-Arroume N. Obtaining antimicrobial peptides by controlled peptic hydrolysis of bovine hemoglobin. Int J Biol Macromol. 2011;49(2):143-153. doi: 10.1016/j.ijbiomac.2011.04.004

9. Przybylski R, Firdaous L, Châtaigné G, Dhulster P, Nedjar N. Production of an antimicrobial peptide derived from slaughterhouse by-product and its potential application on meat as preservative. Food Chem. 2016;211:306-313. doi: 10.1016/j.foodchem.2016.05.074

10. Arroume N, Froidevaux R, Kapel R, Cudennec B, Ravallec R, Flahaut $\mathrm{C}$, et al. Food peptides : purification, identification and role in the metabolism. Current Opinion in Food Science. 2016;7:101-107.

11. Przybylski R, Bazinet L, Firdaous L, Kouach M, Goossens JF, Dhulster $P$, et al. Harnessing slaughterhouse by-products: From wastes to high-added value natural food preservative. Food Chemistry. 2020;304:1254

12. Adje E, Balti R, kouach M, Guillochon D, Nedjar-Arroume N. $\alpha$ 67-106 of bovine hemoglobin : a new family of antimicrobial and angiotensin I-converting enzyme inhibitory peptides. Eur Food Res Technol. 232(4):637-646

13. Lantz I, Glamsta EL, Talback L, Nyberg F. Hemorphins derived from haemoglobin have an inhibitory on angiotensin converting enzyme activity. FEBS Lett. 1991;287(1-2):39-41.

14.Zhao Q Sannier F, Garreau I, Lecoeur C, Piot JM. Reversed-phase high-performance liquid chromatography coupled with second-order derivative spectroscopy for the quantitation of aromatic amino acids in peptides: application to hemorphins. Journal of Chromatography A. 1996;723(1): 35-41

15. Zhao Q Piot JM, Gautier V, Cottenceau G. Isolation and characterization of a bacterial growthstimulating peptide from a peptic bovine hemoglobin hydrolysate. Appl Microbiol Biotechnol. 1996;45(6):778784.

16. Ivanov V, Andrei T, Karelin A, Mikhaleva I, Vaskovsky B V, Sviryaev VL. Isolation, structure and properties of endogenous peptides. Bioorg 
Khim. 1992;18(10-11):1271-1311.

17. Najafian L, Babji AS. Production of bioactive peptides using enzymatic hydrolysis and identification anti oxidative peptides from patin (pangasius sutchi) sarcoplasmic protein hydolysate. Journal of Functional Foods. 2014;9:280-289.

18. Crosby WH, Mann JI, Furth FW. Standardizing a method for clinical hemoglobinomery. US Armed Forces Med J. 1954;5(5):693-703.

19. Dubois V, Nedjar-Arroume N, Guillochon D. Influence of PH on the appearance of active peptides in the course of peptic hydrolysis of bovine haemoglobin. Prep Biochem Biotechnol. 2005;35(2):85-102.

20. Choisnard L, Froidevaux R, Nedjar-Arroume N, Lignot B, VercaigneMarko D, Krier F, et al. Kinetic study of the appearance of an antibacterial peptide in the course of bovine haemoglobin peptic hydrolysis. Biotechnol Appl. Biochem. 2002;36(3):187-194.

21. Molyneux P. The use of the stable free radical diphenylpicrylhydrazyl (DPPH) for estimating antioxidant activity. Songklanakarin J Sci Technol. 2004;26(2):211-219.

22. Linderstrom-Lang K. Proteins and Enzymes III (S.L.M. Lectures Ed.). 1952.

23. Piot JM, Zhao Q Guillochon D. Isolation and characterization of two opioid peptides from a bovine hemoglobin peptic hydrolysate. Biochemical and biophysical research communications. 1992;189(1):101-110.

24. Takagi H, Shiomi H, Fukui K, Hayashi K, Kiso Y, Kitagawa K. Isolation of a novel analgesic pentapeptide, neo-kyotorphin, from bovine brain. Life sciences. 1982;31(16-17):1733- 1736.

25. Caron J, Cudennec B, Domenger D, Belguesmia Y, Flahaut C, Kouach M, et al. Simulated GI digestion of dietary protein: release of new bioactive peptides involved in gut hormone secretion. Food Research International. 2016;89(1):382-390.

26. Barkhudaryan N, Kellermanna J, Galoyanb A, Lottspeich F. High molecular weight aspartic endopeptidase generates a coronaroconstrictory peptide from the béta chain of hemoglobin. FEBS Letters. 1993;329(1-2):215-218.

27. Kagawa K, Matsutaka H, Fukuhama C, Watanabe Y, Fujino H. Globin digest, acidic protease hydrolysate, inhibits dietary hypertriglyceridemia and Val-Val-Tyr-Pro, one of its constituents, possesses most superior effect. Life Sci. 1996;58(20):1745-1755.

28. Yaba Adje E, Balti R, Kouach M, Guillochon D, Nedjar-Arroume N. a67-106 of bovine hemoglobin, a new family of antimicrobial and angiotensin I-converting enzyme inhibitory peptides. Eur Food Res Technol. 2011;232(4):637-646.

29. Blishchenko EY, Mernenko OA, Yatskin ON, Ziganshin RH, Philippova MM, et al. Neokyotorphin and neokyotorphin (1-4): secretion by erythrocytes and regulation of tumor cell growth. FEBS Letters. 1997;414(1):125-128.

30. Hao Y, Yang N, Wang X, Teng D, Mao R, Wang X, et al. Killing of staphylococcus aureus and salmonella enteritidis and neutralization of lipopolysaccharide by 17 residue bovine lactoferricins: improved activity of trp/ala-containing molecules. Sci Rep. 2017;7:44278. doi: 10.1038/srep44278

31.Zhao S, Qaiyumi S, Friedman S, Singh R, Foley SL, White DG, et al. Characterization of salmonella enterica serotype Newport isolated from humans and food animals. J Clin Microbiol. 2003; 41(12):53665371.

32. Jean C. Activité antimicrobienne de peptides provenant d'hydrolysats de protéines de babeurre, de lactoferrine et de pois. Thesis dissertation, University of Montreal. 